\title{
The Critical Point of Regional Policies, Government trade-offs, and Policy Effectiveness
}

\author{
Lizhao $\mathrm{Du}^{1,2, \mathrm{a}^{*}}$ \\ ${ }^{1}$ School of Economics, Sichuan University, Chengdu, China \\ ${ }^{2}$ School of Economics and Management, Lanzhou Jiaotong University, Lanzhou, China \\ aaduw@126.com
}

Keywords: Regional policy; Government balance; Policy effect.

\begin{abstract}
Through the establishment of a two-region model, this paper analyzes the critical conditions for the implementation of the policy of narrowing regional disparities by means of financial transfer payments. The key to improving the effectiveness of regional policies is to find ways to further optimize the structure of fiscal transfer payments, continuously change the incentive mechanism of local officials, and maintain a dynamic adjustment of transfer payment policies.
\end{abstract}

\section{Introduction}

Achieving a coordinated and balanced development of the regional economy is an important goal and strong will of a country's central government. Supporting the region's economic development through large-scale financial transfer payments in underdeveloped regions is the main policy for the central government to narrow the regional development gap. tool. This raises two questions: First, does the central government have sufficient financial capacity to implement fiscal transfer payments; and second, does fiscal transfer payments help narrow regional disparities? These two issues can actually be summarized as two "critical points", that is, the critical point for the introduction of policies by the state to narrow regional disparities by means of fiscal transfer payments and the critical points at which these policies produce practical results. Existing studies have separately studied these two issues [1]. In reality, these two issues are logically continuous and inherited. They are all influenced by many external factors such as the game of interests between the central government and local governments [2], the cooperation and competition between developed regions and underdeveloped regions [3], the balanced development of regional economies and the trade-offs of overall economic efficiency, and so on. The introduction of a policy of narrowing regional development gaps and the emergence of policy effects have an intrinsically consistent mechanism of action. The purpose of this paper is to use a series of regional assistance policies implemented by China as an example. Through the establishment of a unified analytical framework, under the conditions of a series of characteristics of China's economic growth, we will explore the specific constraints and costs of the "two critical points". The comparison of benefits provides a microscopic examination perspective for reducing the effect of regional disparities policy.

This article sets the main body of policy to implement the policy of narrowing regional development gaps, which is the government (including the central government and local governments). The central government promotes the development of underdeveloped areas through transfer payments as its main policy measures. When the income of the underdeveloped areas reaches the national average, the increase in income will have a demand-initiated effect, and the changes in social welfare before and after the implementation of the policy can be examined accordingly. In the model of this paper, the following issues are considered: (1) Government officials are the main actors in implementing regional policies, promoting regional development, and managing regional issues; (2) Fiscal transfer payments are the most important policy for the central government to support the development of backward regions; (3) Competition among local governments and conflicts of interest arising from the political promotion system will affect the 
effectiveness of the implementation of policies; (4) China's regional development imbalances not only exist between the Eastern and Western Regions, but also within each region. There is a serious dual economic problem, which leads to the complexity of regional policies and coverage; (5) The regional factor flow will have an important impact on the regional development gap and the policy implementation to narrow the regional development gap. The model proves that under the condition of incompatibility of incentives and constraints, multiple game relations will be generated in the implementation of the Western Development Strategy. Different interests based on the optimal tactics of maximizing their own interests cannot produce the combined effect of narrowing regional disparities. Instead, they will To a large extent, it will offset or reduce policy efforts to narrow the development gap in the region. Therefore, the mere desire to rely solely on fiscal transfer payments cannot achieve the harmonious and balanced development of the regional economy. It needs to consider more policy support and reform issues.

\section{Basic Assumptions and Background Description}

The disparity in per capita income between the eastern, central and western regions is the main manifestation of the uncoordinated regional economy in China. Therefore, the development of the western region is a priority in China's regional development strategy. Its main mode of implementation is to promote the development of the western region by increasing the transfer of payments to the western region, and to reduce the income gap between the western region, the eastern region, and the entire country. According to the development level, the country is divided into A and B regions. Region A is the rest of the country except the western region. Region B represents the western region. Region $\mathrm{A}$ has a higher level of development than Region $\mathrm{B}$. Assume that the per capita income of area $\mathrm{A}$ is $y^{A}$, the employment of area $\mathrm{A}$ accounts for $1-\theta$ the total population, the per capita income of area B is $y^{B}$, and the employment of area B accounts for $\theta$ the total population, and $0<\theta<1$. For ease of analysis, we normalize the population of regions $\mathrm{A}$ and $\mathrm{B}$ to 1 so that the total population of the country can be counted as 2 .

From the national level to the regional level, the dual economic phenomena are extremely prominent, mainly reflected in the differences in the level of development between the modern industrial economy and the traditional agricultural economy, and between urbanized areas and rural areas. The scores for the relatively developed economic sectors and regions in the eastern and western regions are recorded as $\mathrm{m}$, and the relatively less developed economic sectors and regions are recorded as $\mathrm{n}$. The total population of the eastern and western regions is standardized to 1 and the total national population is 2 . The per capita income of the $\mathrm{m}$ departments (regions) in the eastern region is $y_{m}$, and the employment of the $\mathrm{m}$ departments (regions) accounts for $1-\theta_{n}^{A}$ the total population; the per capita income of the $\mathrm{n}$ departments (regions) in the eastern region is $y_{n}$, and the employment of $\mathrm{n}$ departments (regions) accounts for $\theta_{n}^{A}$ the total population, and $0<\theta_{n}^{A}<1$. The per capita income of the $\mathrm{m}$ departments (regions) in the western region is $y_{m}$, the employment of the $\mathrm{m}$ departments (regions) accounts for $1-\theta_{n}^{B}$ the total population; the per capita income of the $\mathrm{n}$ departments of the western region is $y_{n}$, the number of people employed in the $\mathrm{n}$ sector accounts for $\theta_{n}^{B}$ the total population, and $0<\theta_{n}^{B}<1$. For the time being, the model does not consider the difference between the per capita income of the $\mathrm{m}$ and $\mathrm{n}$ departments in the east and the west. It is assumed that the differences between the eastern and western regions are only reflected in the proportion of $\theta_{n}^{A}<\theta_{n}^{B}$, which means that the proportion of the population of the $\mathrm{n}$ sector in the eastern region is smaller.

The development goals and policies formulated by the central government require the support, implementation, and implementation of local governments, and ultimately rely on the efforts of local governments. Under the political economics of "high political concentration and economic decentralization," local officials often face political and economic incentives and respond to them. 
On the one hand, local officials must work hard to promote economic growth in the area to win in the political promotion competition; on the other hand, they must implement the strategic task of the central government in coordinating regional development. Although from a global perspective, the coordinated regional pattern and a unified domestic market are conducive to exerting economies of scale growth, adopting a strategy of not coordinating with other regions and segmenting the market is a dominant strategy among local governments. The existing system can effectively provide incentives for local officials to develop the economy of their jurisdiction, but there is no corresponding incentive for coordination among jurisdictions. When these two goals conflict, local officials compete for and compete with economic resources for the economic growth of the jurisdiction, resulting in market segmentation and local protectionism, which results in the weakening of the implementation of the western development strategy.

Eliminating administrative divisions between regions and promoting the free movement of capital and labor are important ways to establish a unified national market, deepen division of labor and cooperation, and improve economic efficiency. Cross-regional mobility of capital and labor is also an important factor affecting the coordinated development of China's regions. In the west, the government-led net inflow of capital greatly exceeds the outflow of private capital, so that the western region can maintain a relatively high investment rate. However, the flow of private capital from the west to the east shows that there is a gap in the marginal income of capital between the eastern and western regions. When the capital accumulation in the eastern region has not yet reached the stage of diminishing returns to scale, the government's intervention has led to the flow of capital to the western regions with lower returns, which will undoubtedly damage the overall economic efficiency of the country. This is also an inevitable requirement for the implementation of the strategy for the development of the western region. The cost paid will affect the implementation of the policy. More than $68 \%$ of the trans-provincial migration of the labor force in the western region is concentrated in the eastern region. On the one hand, the gap between per capita income is reduced between the east and the west by reducing the "denominator". On the other hand, the scale and standard of fiscal transfer payments are affected by changes in the population structure. Such as the impact, and thus affect the process of narrowing regional disparities and the continuity of the policy.

\section{Financial Conditions}

Assuming that the central government supports the development of $\mathrm{n}$ departments (regions) by collecting taxes from the $\mathrm{m}$ departments (regions) of the eastern and western regions, the central government's tax capacity is a very important constraint. Taking into account the narrowing of the income gap and the start-up effect of residents' needs in the $\mathrm{n}$ departments (regions) and the overall welfare level of the whole society, if the central government's taxation ability is strong enough, it is feasible to support the development of $\mathrm{n}$ departments (regions); The lack of taxation ability of the central government will not support the development of $n$ departments (regions). Assume that the central government imposes a tax rate of $t$ on $m$ departments (regions), and this tax rate does not jeopardize the sound development of $\mathrm{m}$ departments (regions). The total tax revenue $\mathrm{T}$ of the central government actually represents the central government's taxation ability. It should be emphasized that the model standardizes the total number of people in the eastern and western regions to one, and that transfer payments require social costs $\lambda$.

The total revenue of the central government is:

$$
T=t\left[\left(1-\theta_{n}^{A}\right) y_{m}+\left(1-\theta_{n}^{B}\right) y_{m}\right]
$$

The employment population of the $\mathrm{n}$ departments (regions) in the country is:

$$
N=\theta_{n}^{A}+\theta_{n}^{B}
$$

Regardless of the eastern region or the western region, when $\frac{T}{N(1+\lambda)}+y_{n} \geq \bar{y}$, regional policies led by the central government to support the development of $\mathrm{n}$ sectors (regions) in each 
region will have a priming effect on residents' needs in $\mathrm{n}$ sectors (regions). We can get:

$$
T \geq N(1+\lambda)\left(1-\frac{\theta_{n}^{A}}{2}-\frac{\theta_{n}^{B}}{2}\right) \Delta y
$$

Among them, the eastern region needs transfer payments from the central government:

$$
T^{A} \geq \theta_{n}^{A}(1+\lambda)\left(1-\frac{\theta_{n}^{A}}{2}-\frac{\theta_{n}^{B}}{2}\right) \Delta y
$$

The western region needs the transfer from the central government as:

$$
T^{B} \geq \theta_{n}^{B}(1+\lambda)\left(1-\frac{\theta_{n}^{A}}{2}-\frac{\theta_{n}^{B}}{2}\right) \Delta y
$$

For analysis convenience, make:

$$
\begin{aligned}
& \bar{T}=N(1+\lambda)\left(1-\frac{\theta_{n}^{A}}{2}-\frac{\theta_{n}^{B}}{2}\right) \Delta y \\
& \bar{T}^{A}=\theta_{n}^{A}(1+\lambda)\left(1-\frac{\theta_{n}^{A}}{2}-\frac{\theta_{n}^{B}}{2}\right) \Delta y \\
& \bar{T}^{B}=\theta_{n}^{B}(1+\lambda)\left(1-\frac{\theta_{n}^{A}}{2}-\frac{\theta_{n}^{B}}{2}\right) \Delta y
\end{aligned}
$$

We can get: $\bar{T}=\bar{T}^{A}+\bar{T}^{B}, \bar{T}^{A}<\bar{T}^{B}$

Assume that the central government performs the same level of transfer payments to the $n$ departments (regions) of the eastern and western regions:

At that time $T \geq \bar{T}$, the central government could transfer payments to the $\mathrm{n}$ departments (regions) of the eastern and western regions at the same time to support the development of $n$ departments (regions), so that the $\mathrm{n}$ departments (regions) in the eastern and western regions could all have a resident consumption start effect.

At that time $\bar{T}^{A} \leq T<\bar{T}$, the central government only supported the development of $\mathrm{n}$ departments (regions) in the eastern region, and the eastern region could have a resident consumption effect.

At that time $T<\bar{T}^{A}$, the Central Government was unable to support the $\mathrm{n}$ departments (regions) of the two regions, and neither of them would have the resident consumption effect.

From the above analysis you can get Proposition 1:

Proposition 1: From the perspective of the central government's taxation ability, at the time $T \geq \bar{T}$, the central government could transfer payments to the n departments (regions) of the eastern and western regions; at the time $\bar{T}^{A} \leq T<\bar{T}$, the central government only supported the development of $\mathrm{n}$ departments (regions) in the eastern region; when $T<\bar{T}^{A}$ The Central Government has no ability to support the $\mathrm{n}$ departments (regions) of the two regions.

Proposition 1 shows that whether the central government supports $\mathrm{n}$ sector (region) development depends critically on its own taxation capacity. Because of $\bar{T}^{A}<\bar{T}^{B}$, the Central Government will first conduct transfer payments in the eastern region to support the development of the $n$ departments (regions) in the eastern region. Only when the time $T \geq \bar{T}$ comes, the central government will increase transfer payments to the western region and support the development of $n$ departments (regions) in the western region. This is also the economic condition proposed and implemented by the Western Development Strategy. From this we get Corollary 1:

Corollary 1: Regarding the taxation capacity of the central government, its critical value increases with the social cost of transfer payments, and increases with the increase in the average income gap between $\mathrm{m}$ and $\mathrm{n}$. 
Proof: For partial guidance $\bar{T}=N(1+\lambda)\left(1-\frac{\theta_{n}^{A}}{2}-\frac{\theta_{n}^{B}}{2}\right) \Delta y=\left(N-\frac{N^{2}}{2}\right)(1+\lambda) \Delta y$ we can get:

$$
\frac{\partial \bar{T}}{\partial \lambda}=N\left(1-\frac{\theta_{n}^{A}}{2}-\frac{\theta_{n}^{B}}{2}\right) \Delta y>0, \frac{\partial \bar{T}}{\partial \Delta y}=N(1+\lambda)\left(1-\frac{\theta_{n}^{A}}{2}-\frac{\theta_{n}^{B}}{2}\right)>0
$$

when $N \geq 1, \frac{\partial \bar{T}}{\partial N}=(1-N)(1+\lambda) \Delta y \leq 0$;

when $N<1, \frac{\partial \bar{T}}{\partial N}=(1-N)(1+\lambda) \Delta y>0$

Assumes $\Delta y=y^{A}-y^{B}>0$ represent the average income gap between regions $\mathrm{A}$ and $\mathrm{B}$. This results in the per capita income of the country as:

$$
\bar{y}=(1-\theta) y^{A}+\theta y^{B}
$$

\section{Actual Conditions}

In the process of implementing western development, when the per capita income of unit area B reaches the national average, it can produce a unit-initiated effect on the consumption of residents in area B. This priming effect is caused by the increase of income in area B. The employed population can consume more social products and services. Prior to the implementation of the Western Development Strategy, the total social welfare was:

$$
W^{0}=2\left[(1-\theta) y^{A}+\theta y^{B}\right]
$$

Assume that the unit cost of implementing the Western Development Program is $(1+\lambda)\left(\bar{y}-y^{B}\right)$, which $\lambda$ indicates the social cost of the transfer payment $(\lambda>0)$. If the proportion of beneficiaries of Region $B$ to the total population of Region $B$ after the major development is $z$, then the total social welfare is:

$$
\begin{aligned}
W^{1} & =2\left[(1-\theta) y^{A}+\theta y^{B}-(1+\lambda)\left(\bar{y}-y^{B}\right) z+\left(\bar{y}-y^{B}\right) z+\mu z\right] \\
& =2\left[(1-\theta) y^{A}+\theta y^{B}-\lambda\left(\bar{y}-y^{B}\right) z+\mu z\right] \\
& =2\left[(1-\theta) y^{A}+\theta y^{B}-\lambda(1-\theta)\left(y^{A}-y^{B}\right) z+\mu z\right]
\end{aligned}
$$

From a global perspective, only by $W^{1} \geq W^{0}$ implementing policies that narrow regional disparities can we improve overall social welfare. The conditions for implementing the policy of narrowing regional disparities can thus be obtained:

$$
\mu \geq \lambda(1-\theta)\left(y^{A}-y^{B}\right)
$$

Here, $\lambda(1-\theta)\left(y^{A}-y^{B}\right)>0$ instead of equal to 0 , because $\lambda>0,0<\theta<1, \Delta y=y^{A}-y^{B}>0$. The unit start-up effect, rather than the overall start-up effect, indicates that the implementation of the Western Development Program is a dynamic process. The beneficiary groups can only gradually expand from a small part of the population. Not all the population of Region B can benefit and increase their income to National average.

For the analysis of convenience, order $\bar{\mu}=\lambda(1-\theta)\left(y^{A}-y^{B}\right)=\lambda(1-\theta) \Delta y$, when $\mu>\bar{u}$, $z^{*}=x$, and the degree of implementation of the policy $f^{*}=\frac{x}{x}=1$; when $\mu=\bar{u}, z^{*} \in[0, x]$, the degree of implementation of the policy $f^{*} \in[0,1]$; when $\mu<\bar{u}, z^{*}=0$, the degree of implementation of the policy $f^{*}=\frac{0}{x}=0$. This gives Proposition 2 .

Proposition 2: From a global perspective, when $\mu>\bar{u}$ the implementation of the Western 
Development Strategy can improve overall social welfare at that time; at that time $\mu<\bar{u}$, implementing the Western Development Strategy may result in the loss of total social welfare. At that time $\mu=\bar{u}$, the implementation of the strategy of developing the western region will neither improve the total social welfare nor bring about the loss of total social welfare.

Based on Proposition 2, Corollary 2 can be obtained.

Corollary 2: From a national perspective, the benefits and effectiveness of the implementation of the Western Development Program will decrease with the increase in the social cost of transfer payments, decrease with the increase of the population in the eastern region, and the average income level between the eastern and western regions. The gap has narrowed down.

Proof: The bigger $\bar{u}$, the more difficult it is to implement the development of the western region, and the smaller the effectiveness and likelihood of continued implementation. The definition of $\bar{u}$, we can get $\frac{\partial \bar{u}}{\partial \lambda}=(1-\theta) \Delta y>0, \frac{\partial \bar{u}}{\partial(1-\theta)}=\lambda \Delta y>0, \frac{\partial \bar{u}}{\partial \Delta y}=\lambda(1-\theta)>0$ 。

It can be seen from the national perspective that the greater the cost of transfer payments in the implementation of the development of the western region, the smaller the benefits and effectiveness of the development of the western region, and the lowering of the total welfare level of society; the gradient of industrial development in the eastern and western regions and the gradual establishment of a unified national market Under the circumstances, the flow of people from the west to the east is a long-term and inevitable trend. With the increase in population in the east and the decrease in the population in the west, the income and effectiveness of continuing to promote the development of the western region through increasing transfer payments will gradually decrease, and the overall social welfare level will also be reduced. Will be affected; through the implementation of the Western Development Strategy, if the gap between the average income levels of the East and West is effectively narrowed, the further increase in transfer payments to promote the development of the western region will become smaller, and the policy contraction and gradual withdrawal should be considered.

\section{Conclusions and Analysis}

Since the reform and opening up, while China's economy has grown at a rapid rate, the regional income gap has been increasing. By 1999, the relative difference coefficient of China's provincial GDP per capita reached 0.90 , and the internationally recognized relative difference coefficient was above and below 0.60. Although the central government has always had a strong willingness to narrow the regional disparity, the fiscal decentralization since the reform has made the central government's financial capacity very weak. Except for the expenditure at this level, it is almost impossible to transfer payments to backward areas. For example, the central government's fiscal revenue accounted for the entire country in 1993 . The proportion of fiscal revenue is only $22 \%$, and transfer payments account for no more than $4 \%$ of the total expenditure of the central government. The tax-sharing reform that began in 1994 effectively improved the state of the central government's revenue. The proportion of the central government revenue to the national fiscal revenue reached $55 \%$, and then remained stable at more than $50 \%$ for a long time. After five years of accumulation, the central government began implementing the strategy of western development in 1999 and supported large-scale transfer payments to support economic development in the underdeveloped western regions. It can be seen that the improvement of the central financial capacity is the critical condition for the central government to promote the coordinated development of the regional economy.

However, whether the central fiscal transfer payment can effectively promote economic growth in underdeveloped areas and positively impact the narrowing of the regional gap still faces many constraints. First, fiscal transfer payments have a positive effect on short-term economic growth in the backward areas of western China, but at the same time, they will also bring about many negative effects, including efficiency loss, government scale expansion, financial dependence, and local 
revenue and expenditure asymmetry. These constitute the cost of transfer payments. When the total return of transfer payments is less than or equal to the total cost, the effectiveness of the western development policy will be greatly reduced. Second, in the dual economy, local governments are faced with both economic and political incentives. In promoting economic development in the area and coordinating economic relations with other regions, they often resort to local protectionist strategies that divide the market, which is not conducive to narrowing the region. The implementation of the gap policy effect. Third, in the event of full mobility of factors, especially the large-scale migration of western populations to the east, it is necessary to continuously adjust the optimal scale of transfer payments to the western region, thus affecting the continuity of transfer payment policies and weakening the overall effect of the western development policy.

The model analysis of this paper has important policy significance. The first is to optimize the distribution structure of transfer payments, prevent rent-seeking and corruption, reduce policy reliance on land transfer, and reduce the overall cost of transfer payments; the second is to change the economic and political incentive mechanisms to make local officials more inclined Coordinate the economic relations among different regions, bring into play the spillover effects between regions, and promote the coordinated development of regional economies. Third, adjust the size, intensity, and structure of transfer payments according to the changing trend of the income gap between the eastern and western regions so that regional assistance policies can be implemented with the best balance between cost and revenue.

\section{Literature References}

[1] Shaoguang Wang and Angang Hu. The Political Economy of Uneven Development: The Case of China,,M.E. Sharpe, Inc.1999.

[2] DeLa Fuente, A. and X. Vives. Regional policy and Spain [J]. Economic Policy, 1995,10 (20) :13-51.

[3] Garcia-Mila, T. and Therese J. McGuire. Do interregional transfers improved the economic performance of poor regions?The case of Spain,Revised Draft:December 27,1996.

[4] Yu D, Peng L. When does Inferring Reputation Probability Countervail Temptation in Cooperative Behaviors for the Prisoners' Dilemma Game? [J]. Chaos, Solitons \& Fractals, 2015, 78: 238-244. 